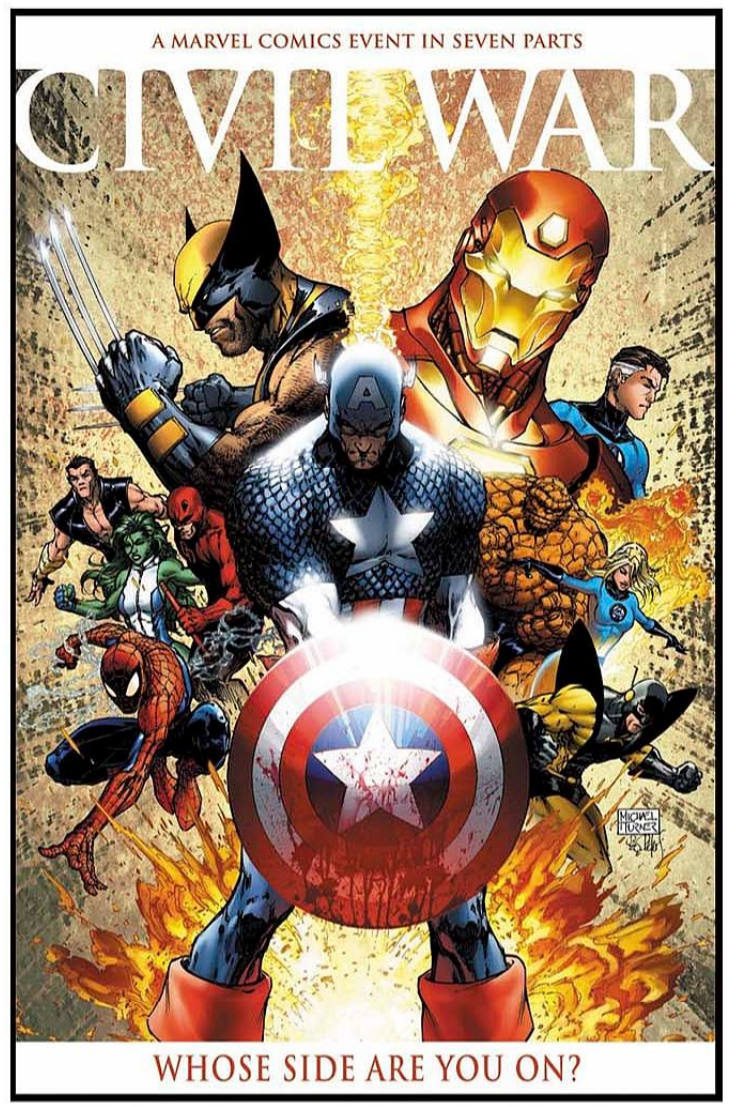

Marvel Comics. llustração da série Guerra Civil, s.d. Disponível em: http://sidekickedcomics.files.wordpress.com/2009/12/civil-war-200602 09074640053.jpg. Acesso em: 22 dez. 2014.

\title{
POLÍTICA E TERRORISMO NA SÉRIE GUERRA CIVIL DA MARVEL COMICS
}

\section{Victor Callari}

Mestrando em História e Historiografia na Universidade Federal de São Paulo sob orientação da professora Dra. Ana Lúcia Lana Nemi e professor de História e Linguagens e História Contemporânea no curso de História do Centro Universitário das Faculdades Metropolitanas Unidas (FMU). Contato: victorcallari@hotmail.com. 
CAШARI, Victor. Política e terrorismo na série Guerra Civil da Marvel Comics. Domínios da Imagem, Londrina, v. 8, n. 16, p. 146-167, jun./dez. 2014.

ISSN 2237-9126

Recebido em 09/01/2014 e a provado em 03/05/2014

\section{Resumo}

O presente artigo analisa o discurso e o posicionamento político adotado pela editora Marvel Comic s em relação às questões referentes ao contexto estadunidense pós 11 de setembro a partir de um estudo das representações construídas sobre os atentados e das subsequentes polític as a ntiterroristas a dotadas pela administra ção Bush presentes na série Civil War, além de discutir aspectos e elementos metodológicos e teóricos que compõem a relação entre História e Quadrinhos.

Palavras-chave: Histórias em quadrinhos. 11 de setembro. Representações.

\section{Abstract}

This article analyzes the discourse and the political position adopted by publisher Marvel Comics on the issues pertaining to the U.S. post-September 11 context from a study of representations built on the attacks and the subsequent anti-temorist policies adopted by the Bush administration and present at the series Civil War, besides to discuss methodological and theoretical aspects and elements that make up the relationship between history and Comics.

Keywords: Comic books. September 11. Representations.

\section{A Saga Civil Ware o contexto pós 11 de Setembro}

O historiador inglês Eric Hobsbawm (2011) afimou que "A queda das torres do World Trade Center foi certamente a mais abrangente experiência de catástrofe que se tem na história, inclusive porter sido acompanhada em cada a parelho de televisão, nos dois hemisférios do planeta", enquanto que Jordan Rendell Smith, professor de literatura inglesa na Queen's University, aprofundando a leitura do evento disse:

In the late twentieth century, the number "911" evoked associations of trauma and panic in emergency calls for help. Ronald Reagan even designated September 11th a "9-1-1 Emergency Telephone Number Day" in 1987. Exactly fourteen years later, the meaning of this number was dramatically overwritten to signify a much greater trauma: not only the surprise terrorist attacks on the architectural symbols of America's economic and military might-the World Trade Center in New York City and the Pentagon in Washington D.C.-but also the nomalized nightmare of twenty-first century history. The "post-9/11 world" stamps itself in the daily news headlines with reports of increased violence and political turmoil worldwide, anxieties of global proportions, and the replacement of once-sacrosanct civil 
CAШARI, Victor. Política e terrorismo na série Guerra Civil da Marvel Comics. Domínios da Ima gem, Londrina, v. 8, n. 16, p. 146-167, jun./dez. 2014.

ISSN 2237-9126

liberties with an unassailable regime of "security," ostensibly to prevent further ac ts of terrorism. (SMITH, 2008). ${ }^{1}$

Foi precisamente nesse contexto de privação dos direitos civis em prol da segurança da nação diante do perigo terrorista que a saga Civil War foi escrita e publicada. Lançada entre os meses de julho de 2006 e janeiro de 2007, foi um dos maiores crossovers² produzidos pela editora Marvel, com repercussões em jomais e outros meios de comunic ação de massa.

A obra alcançou ainda a maior tiragem de uma história em quadrinhos na década, perdendo seu posto apenas em janeiro de 2009 para a edição que trazia o encontro do recém eleito presidente Barack Obama e o icônico personagem Homem-Aranha. As representações³ construídas pelos a rtistas responsá veis pela obra, Mark Millar e Steve Mcniven $(2010)^{4}$, foram supervisionadas pelo editor chefe da editora, Joe Quesada; suas escolhas tiveram consequências em todos os outros selos da editora,

1 “No final do século $X X$, o número ' 911 ' evocou associações de trauma e pânico em chamadas de emergência. Ronald Reagan chegou a designaro dia 11 de setembro como o dia do chamado de emergência telefônico em 1987. Exatamente 14 anos depois, o significado deste número foi drasticamente substituído para significar um trauma ainda maior. não apenas os ataques terroristas surpresa sobre os ś́mbolos arquitetônicos da economia e da força americana - o World Tra de Center em Nova York e o Pentá gono em Washington D.C. - , mas também o pesadelo nomalizado da história do século XXI. $O$ 'mundo pós 11 de setembro' se anuncia em manchetes de notícias diárias com relatos de aumento da violência e agitação política em todo o mundo, tumultos de proporções globais e a substituição das liberdades civis, uma vez sagradas, por um regime ina tacável de segurança para evitar novosatos de terrorismo".

2 Termo utilizado quando personagens de histórias diferentes ou mesmo de editoras diferentes a parecem em uma mesma revista.

3 Utilizaremos o conceito de "representação" tal qual ele vem sendo desenvolvido pelo historiador francês Roger Chartier (2011), a partir do diálogo com as reflexões do so ciólogo Pierre Bourdieu e do conceito de habitus de Norbert Elias, considerando a representação como uma categoria no qual a inteligibilidade do mundo real é organizada e se manifesta a partir das disposições dos diferentes grupos sociais que ora se tornam seus "construtores", ora se tomam seus "receptores", evidenciando assim, a disposição da dominação, da luta pelo poder e pelo controle do poder que se manifesta na tentativa das diferentes classes sociais de impor sua concepção e interpretação do mundo real.

4 Mark Millar é um roteinista de quadrinhos que nasceu na Escócia em 1969. Entrou no mercado estadunidense pela editora DC Comics e ganhou destaque em título da Liga da J ustiça, passou a trabalhar para a Marvel Comics em 2001 e reformulou ostítulos de X-Men e os Vingadores para a linha Ultimate. Já na condição de um dos principais nomes do mercado, Millar publicou obras como Wanted e Kick-Ass, a mbas adaptadaspara o cinema. Steve Mcniven, desenhista, na sceu no Canadá em 1967. Começou sua trajetória na editora Marvel Comics em 2004 destacando-se pelo seu trabalho em Marvel Knights: Quarteto Fantá stic 0. 
CAШARI, Victor. Polític a e terrorismo na série Guerra Civil da Marvel Comics. Domínios da Ima gem, Londrina, v. 8, n. 16, p. 146-167, jun./dez. 2014.

ISSN 2237-9126

evidenciando a importância de coordenação e planejamento da equipe da "casa dasideias".

A história começa com uma equipe de televisão acompanhando um grupo de super-heróis - conhecidos por Novos Guerreiros - em seu cotidia no de combate ao crime, em uma espécie de "reality show" com o intuito de alavancarosíndices de audiência da emissora e a popularidade da equipe, a té então praticamente desconhecida. Com poucos quadros em cada uma das páginas, os artistas optaram por uma narrativa dinâmica, elipses escuras e diálogos curtos e objetivos; há apenas quatro balões compostos nas primeiras sete páginas, dando destaque à qualidade dos desenhos de Mcniven 5 .

Em uma ação impulsiva, o grupo dos Novos Guerreiros entra em confronto com alguns supervilões mais poderosos que eles reconhecidamente poderiam lidar. O resultado da ação inconsequente do grupo é uma explosão deflagrada pelo vilão Nitro, que culmina com a destruição de diversos quarteirões, uma escola e mais de "oitocentas baixas".

Figura 1

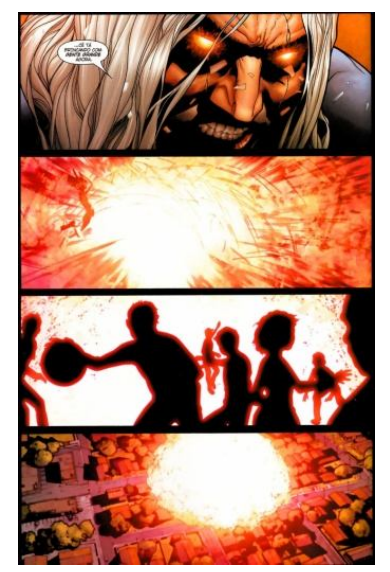

Civil War, 01. Ação "temorista” do vilão Nitro. Nova York: Marvel Comics, 2006.

5 As a nálises das características da linguagem das histórias em quadrinhos é realizada a partir das contribuições teóricas de Will Eisner (2010), Scott Mccloud (2005) e Paulo Ramos (2010). 
CAШARI, Victor. Política e terrorismo na série Guerra Civil da Marvel Comics. Domínios da Ima gem, Londrina, v. 8, n. 16, p. 146-167, jun./dez. 2014.

ISSN 2237-9126

Uma das principais características da narrativa gráfica da obra pode ser observada na imagem acima; páginas metricamente divididas em quatro quadros, com formato retangular - aparentemente uma influência da obra Watchmen, de Alan Moore - altemando enquadramentosfechados que privilegiam expressões denotadoras de sentimentos ou personalidade das personagens com planos abertos capazes de intensificar a ação e seus resultados. A essa diagramação padrão altemam-se páginas cheias ou duplas, além de pequenas variações da divisão quadro retangular tradicional.

\section{Figura 2}

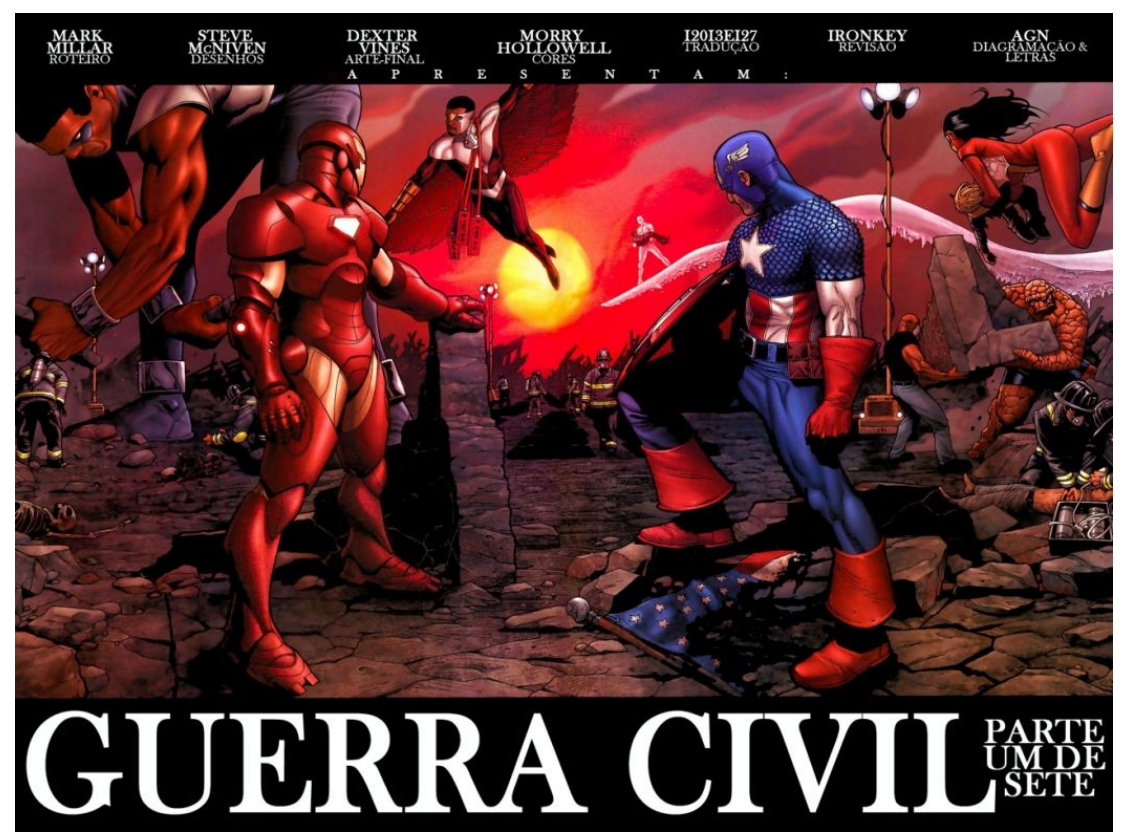

Civil War, 01. Destruição a pós o ataque terrorista. Nova York: Marvel Comics, 2006.

A imagem acima, exemplo de páginas duplas na obra, já evidencia um dos elementos norteadores da trama que seria desenvolvida ao longo da série. Em la dos opostos da imagem, encontram-se o Homem de Ferro e o Capitão América. Os dois personagens que dividinam os super-heróis entre aqueles a favor da lei de registros e aqueles que passariam à 
CAШARI, Victor. Polític a e terrorismo na série Guerra Civil da Marvel Comics. Domínios da Ima gem, Londrina, v. 8, n. 16, p. 146-167, jun./dez. 2014.

ISSN 2237-9126

clandestinidade são separados pelo Sol, desenhado no centro da imagem com o ponto de fuga conduzindo a o horizonte. A primeira página dupla da revista destaca a destruição perpetrada pelos supervilões e a ação dos super-heróis na tentativa de resgatar os sobreviventes. A explosão de Nitro, nesse momento, evoca enquanto representação a presença dos atentados terronistas ao World Trade Center, as vítimas inocentes e a incapacidade de defesa do govemo dos Estados Unidos, representada pela bandeira destruída embaixo de um dos maiores śmbolos da cultura estadunidense, um Capitão América de cabeça baixa, sem altiveze com o punho cerrado.

O processo que se inicia após esse evento diz respeito à liberdade de atuação dos super-heróis dentro da sociedade. A a tuação desregulamentada dos heróis passa a ser vista com receio pela sociedade civil que manifesta sob diferentes formas sua insatisfação diante da insegurança e do receio de viver não apenas entre vilões com super poderes, mas entre heróis que não respondem publicamente por seus atos.

Figura 3

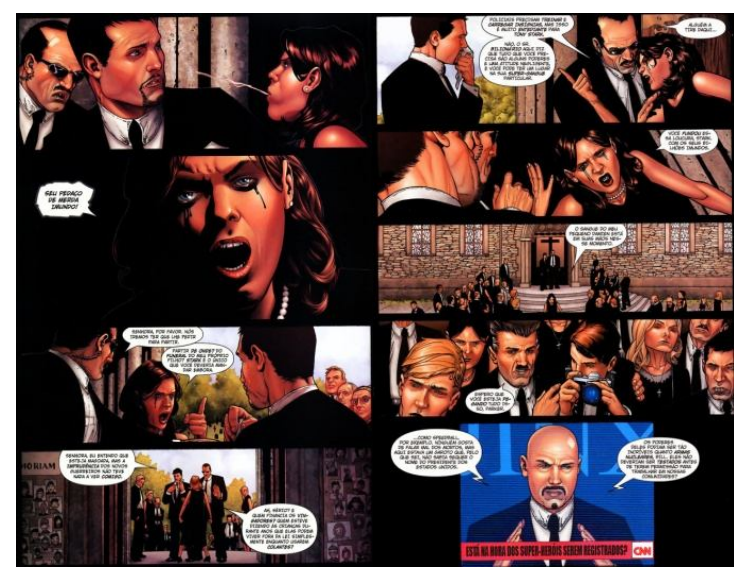

Civil War, 01. Velónio dos mortos no atenta do. Nova York: Marvel Comics, 2006.

Nas imagens a cima é possível observar Tony Stark, o Homem de Ferro, sendo responsabilizado pela mãe de uma das vítimas durante o velónio. A escolha por planos fechados permite ao leitor acompanhar de perto as emoções de dor - por parte da mãe - e de surpresa porparte de Tony Stark 
CAШARI, Victor. Polític a e terrorismo na série Guerra Civil da Marvel Comics. Domínios da Ima gem, Londrina, v. 8, n. 16, p. 146-167, jun./dez. 2014.

ISSN 2237-9126

pela responsabilidade a ele atribuída aos eventos. O último quadro da primeira página "emoldura" a ação com a imagem das vítimas, enquanto que na página seguinte é possível perceber a utilização de uma estratégia de substituição da figura do narrador - aquele que informa o leitor através das legendas - pela figura dos meios de comunicação como elemento comunicadordasaçõese do tempo decomido na trama.

O drama de uma mãe que perdeu seu filho no atentado não é o único exemplo dado por Millar. O temore a revolta da sociedade civil, que responde sem ponderar sobre o acontecido, são retratados na sequência em que o personagem Tocha Humana é agredido por homens comuns na fila de uma boate.

Figura 4

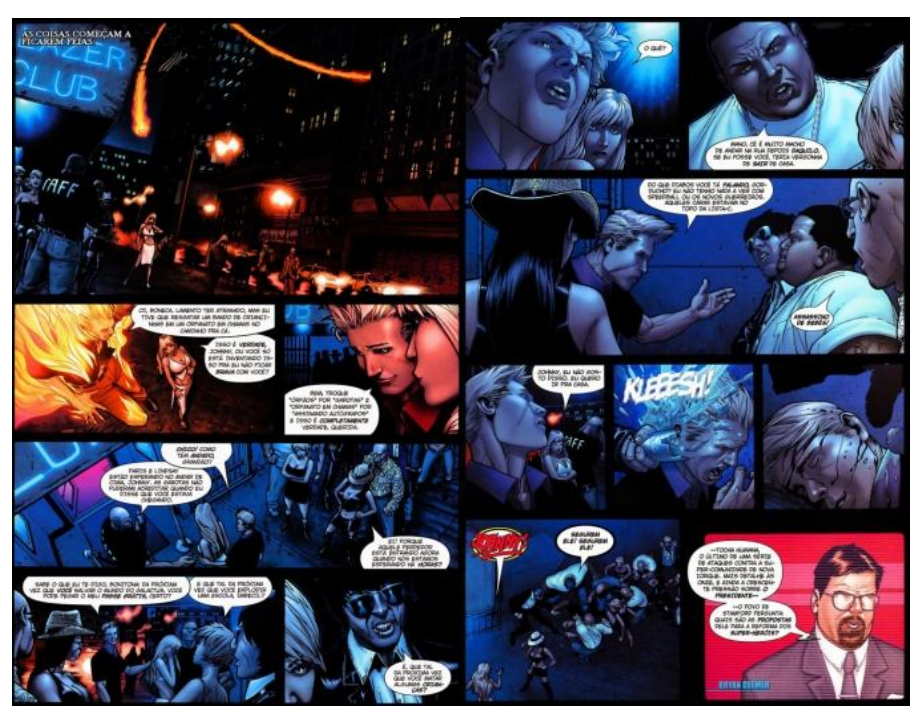

Civil War, 01. Tocha Humana agredido por civis. Nova York: Marvel Comics, 2006.

As consequências cotidianas da ação dos Novos Guerreiros e o a taque temorista do vilão Nitro colocam em ladosopostosa socieda de civil e os super- heróis. É importante destacar o recurso gráfico utilizado por Mcniven no primeiro quadro; a trajetória de fogo é a linha cinética que apresenta o caminho percomido pela personagem, podendo-se a inda frisar a opção por tons de azul para evidenciar a luz artificial em frente à casa 
CAШARI, Victor. Polític a e terrorismo na série Guerra Civil da Marvel Comics. Domínios da Imagem, Londrina, v. 8, n. 16, p. 146-167, jun./dez. 2014.

ISSN 2237-9126

notuma, além, é claro, de mais uma vez o último quadro resenado para a repercussão na mídia .

Enquanto o govemo procura responder à sensação de insegurança e a calmar as massas, os super-heróis são chamadosa a poiar a proposta de lei de registros, que tem como objetivo colocar todos os super-heróis sob a tutela do Estado, obrigando-os a registrarem-se, revelar suas identidades secretas, e tomarem-se verdadeiros funcioná rios públicos. Uma afronta aos direitos individuais e ao discemimento de cada um sobre quem ou o que representaria uma ameaça ao povo. Tal questão levanta uma referência clara e direta a o Patriot Act ${ }^{6}$ e ao clima de tensão que se instaurou nos Estados Unidos após o 11 de Setembro, em que a suspeita de terrorismo permitiu ao govemo deter suspeitos sem uma acusação formal por mais de setenta e duas horas, grampear ligações mesmo sem autoriza ção formal da justiça, e investigar cidadãos esta dunidenses denuncia dos por seus vizinhos a penas por possuírem ascendência árabe.

Figura 5: Sequencia de eventos que colocam o Capitão América na clandestinidade.

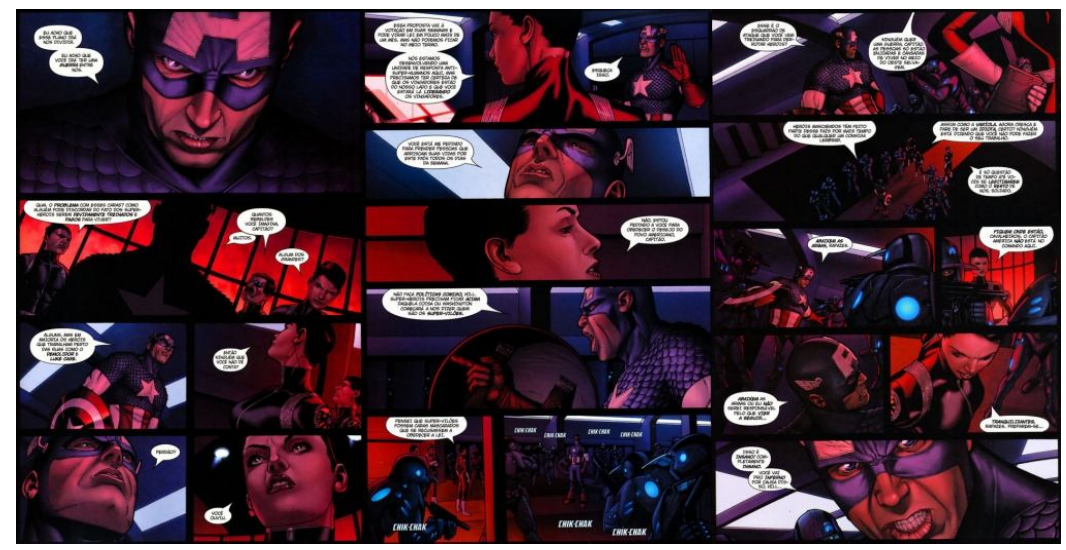

Civil War, 01. Nova York: Marvel Comics, 2006.

\footnotetext{
${ }^{6}$ Este é o nome dado ao ato H. R. 3162, a provado pelo Congresso norte americano no dia 26 de outubro de 2001. Em seu texto, o ato é apresentado como "An act to deter and punish terrorist acts in the United States and around the world, to enhance Law enforcemente investigatory tools, and for other purposes" "Um ato para deter e punir atos terroristas nos Estados Unidos e ao redor do mundo, para melhorar as ferramentas de direito de investiga ção e outros fins" - tradução livre). (UNITED STATES, 2001).
} 
CAШARI, Victor. Política e terrorismo na série Guerra Civil da Marvel Comics. Domínios da Imagem, Londrina, v. 8, n. 16, p. 146-167, jun./dez. 2014.

ISSN 2237-9126
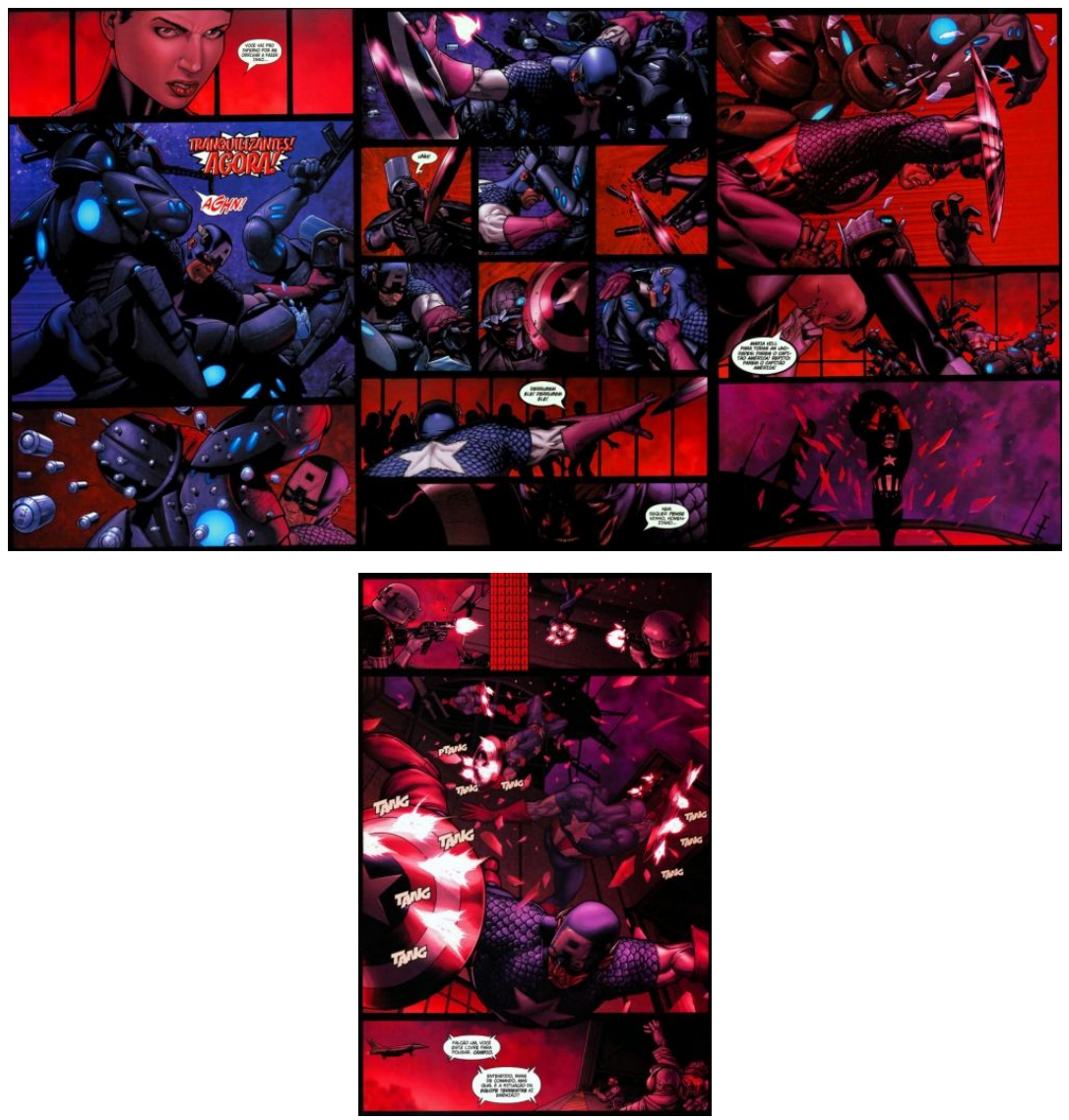

Civil War, 01. Nova York: Marvel Comics, 2006.

A sequência de imagens acima retrata um diálogo entre o Capitão América e a comandante da agência S.H.I.E.LD7, agente Hill8, desenvolvido dentro de uma base aérea da agência. A comandante anuncia a o Capitão América que a lei de registros é uma realidade e que conta com sua participação no controle daqueles heróis que eventualmente se tomassem dissidentes. Para a surpresa da comandante e do leitor menos acostumado com a essência do personagem, o Capitão se recusa a lutar contra seus

\footnotetext{
7 A a gência foi criada por Stan Lee e Jack Kirby, em 1966, e desde 1991 é tra duzida como "Superintendência Humana de Intervenção, Espiona gem, Lo gística e Dissua sã o".

8 "Originally from Chicago Maria Hill joined SHIELD and rose to the position of commander. After_Nicholas Fury's 'Secret War' Maria was chosen to be director of SHIELD by the President himself after he commended her on her work while she was stationed on assignment in Madripoor. Although many others who she herself admitted were better suited for position were not considered for directorship she was assigned director. It has emerged that Maria was chosen as the other candidates were 'Fury Loyalists' and SHELD needed 'new direc tion'". (MARVEL, 2013)
} 
CAШARI, Victor. Política e terrorismo na série Guerra Civil da Marvel Comics. Domínios da Ima gem, Londrina, v. 8, n. 16, p. 146-167, jun./dez. 2014.

ISSN 2237-9126

próprios colegas, colocando-se contra a lei de registros e contra o próprio govemo dos Estados Unidos.

A quantidade de balões de fala utiliza dos conduz o leitor a uma leitura mais atenta dos diálogos em um momento importante da trama, privilegiando nas primeiras três páginasa argumentação das personagens, e nas últimas três páginas a narrativa por meio da ação. No diálogo presente na segunda página, a comandante solic ita o apoio do herói, enquanto esse responde: "você está me pedindo para prender pessoas que a miscam suas vidas por esse país todos os dias da semana". A resposta vem de forma direta: "não, estou pedindo a você para obedecer o desejo do povo americ ano, Capitão".

A escolha dos planos fechados tem por objetivo destacar as expressões das personagens durante os diálogos e denota a ambiguidade da estra tégia escolhida por Millare Mcniven, poisquando a comandante faz uso do apelativo argumento da "vontade do povo americano", o enquadramento em um plano contra-plongée dado ao Capitão América o favorece em detrimento do enquadramento linear dado à própria comandante. A luz que aparece acima da cabeça do Capitão, altemando tons de azul e branco, remete às cores de seu uniforme e à bandeira dos Estados Unidos, enquanto o tom de vemelho ausente manifesta-se nas janelas que iluminam o cenário da base aérea com o pordo sol.

Com o impasse das personagens, os soldados presentes engatilham suas amas, o que pode ser percebido pelo uso da onomatopeia no quadro final da segunda página. A ação tem início na página quatro, fazendo uso de duas narrativas simultâneas desenvolvidas ao longo de toda a página cinco. No primeiro quadro, o personagem do Capitão América a remessa seu escudo com a mão direita, e nos quadros seguintes o leitor a companha, de forma intercalada, o escudo atingindo soldados e amas enquanto Capitão América luta contra outros adversários, teminando com o retomo do escudo às suas mãos. $O$ impacto e os detalhes da luta são enfatizados 
CAШARI, Victor. Polític a e terrorismo na série Guerra Civil da Marvel Comics. Domínios da Ima gem, Londrina, v. 8, n. 16, p. 146-167, jun./dez. 2014.

ISSN 2237-9126

graças aos planos fechados e ao uso das linhas cinéticas de ação, que dinamizam e dão movimento à cena. Na última página Mcniven faz uso, mais uma vez, do recurso de linha cinética para demonstrar a trajetória e o movimento do personagem após sair pela janela até cair em uma aeronave, ao mesmo tempo em que se defende, com seu escudo, das balas dispa radas pelos soldados.

A primeira edição termina com os representantes do govemo reunidos em Washington aprovando a lei de registros e apoiados por três dos ma is inteligentes super-heró is da editora, o Sr. Fantástico, o J aqueta Amarela e, principalmente, $\mathrm{O}$ Homem de Ferro.

$\mathrm{Na}$ segunda edição, a lei de registro entra em vigor e o grupo de super-heróis agora se divide entre aqueles que apoiam o registro, encabeçados pelo Homem de Ferro, e aqueles dissidentes, encabeçados pelo Capitão América. A trama dá espaço para eventos cotidianos e aprofunda os problemas na relação de Sue Storm, a Mulher Invisível, e seu marido Reed Richards, o Sr. Fantástico, mostrando a primeira reticente em relação às consequências da lei e o segundo afimando que "o grande plano de Tony para a comunidade super humana é a coisa mais empolgante na qual já trabalhei, Sue" (MIШAR; MCNIVEN, 2010, p. 40). O roteinista é bastante cuidadoso ao dividir os personagens nos seus respectivos grupos de apoio, evitando ao máximo influenciar o leitor de imediato, escamoteando seu posicionamento político, assim como o da editora, em detalhes na rativos que precisam ser observados de forma minuciosa.

O momento mais importante dessa edição fica a cargo da revelação da identidade secreta do Homem-Aranha, elemento que coloca o grupo a favor do registro junto à opinião pública. Nessa edição, o personagem Homem-Aranha coloca emo a um dos segredos mais bem guardados do Universo Marvel, uma vez que sua experiência havia the ensinado que o conhecimento de sua identidade poderia acarretar problemas a seus familiares e entes queridos. 
CAШARI, Victor. Polític a e terrorismo na série Guerra Civil da Marvel Comics. Domínios da Imagem, Londrina, v. 8, n. 16, p. 146-167, jun./dez. 2014.

ISSN 2237-9126

\section{Figura 6}

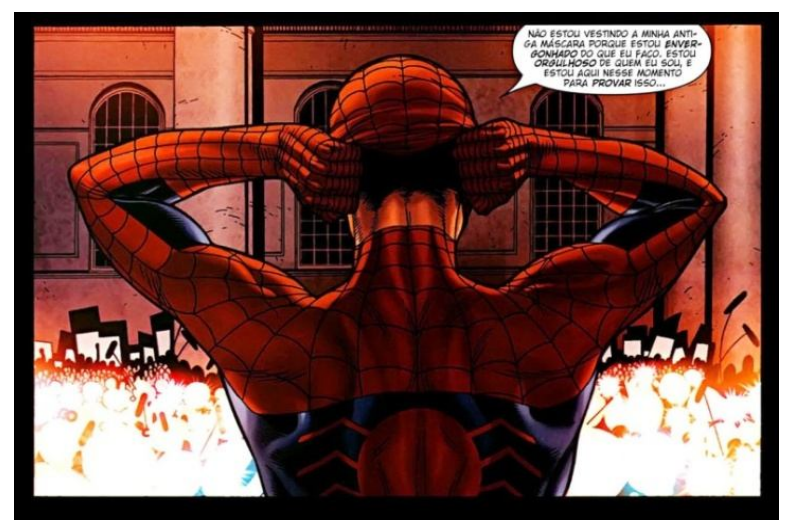

Civil War, 02. Homem-Aranha revela sua identida de secreta. Nova York:

Marvel Comics, 2006.

A terceira edição da série a companha a tentativa dos heróis adeptos à lei de registro de angariar apoio de outros personagens, tal qual o Pantera Negra e os mutantes X-men, a o mesmo tempo em que faz uso dos jomaise dos meios de comunicação para noticiar a ação dos dissidentes que continuam a combater o crime e a promessa de ação do Homem de Ferro de enfrentar esses rebeldes.

Enquanto tomam um café, os super-heróis dissidentes conversam sobre suas novas identidades, e nos dois últimos quadros o Capitão América aponta para uma dasconsequências da lei de registros ao afimar

Só estou pensando em um encontro que tive dez minutos atrás com um garoto da Fundação Faça um Desejo. Eu lhe disse que jogańamos beisebol no quintal dele por um tempinho, mas na certa - lugar está coalhado de mata-capas. Foram as pequenas coisas que nos roubaram com esse lixo de registro, as pequenas coisas que nosfazem quem somos. (MIШAR; MCNIVEN, 2010, p. 65).

Os heróis recebem um chamado de emergência, um incêndio em uma indústria químic a leva o grupo de dissidentespara lá com o objetivo de ajudar os trabalhadores, porém eles se deparam com uma amadilha orquestrada pela S.H.I.E.L.D. e o Homem de Ferro. Os rebeldes são cercados 
CAШARI, Victor. Polític a e terrorismo na série Guerra Civil da Marvel Comics. Domínios da Ima gem, Londrina, v. 8, n. 16, p. 146-167, jun./dez. 2014.

ISSN 2237-9126

e levados a uma tentativa de diálogo entre os líderes dos dois grupos que termina com maisum acontecimento dramático.

Figura 7
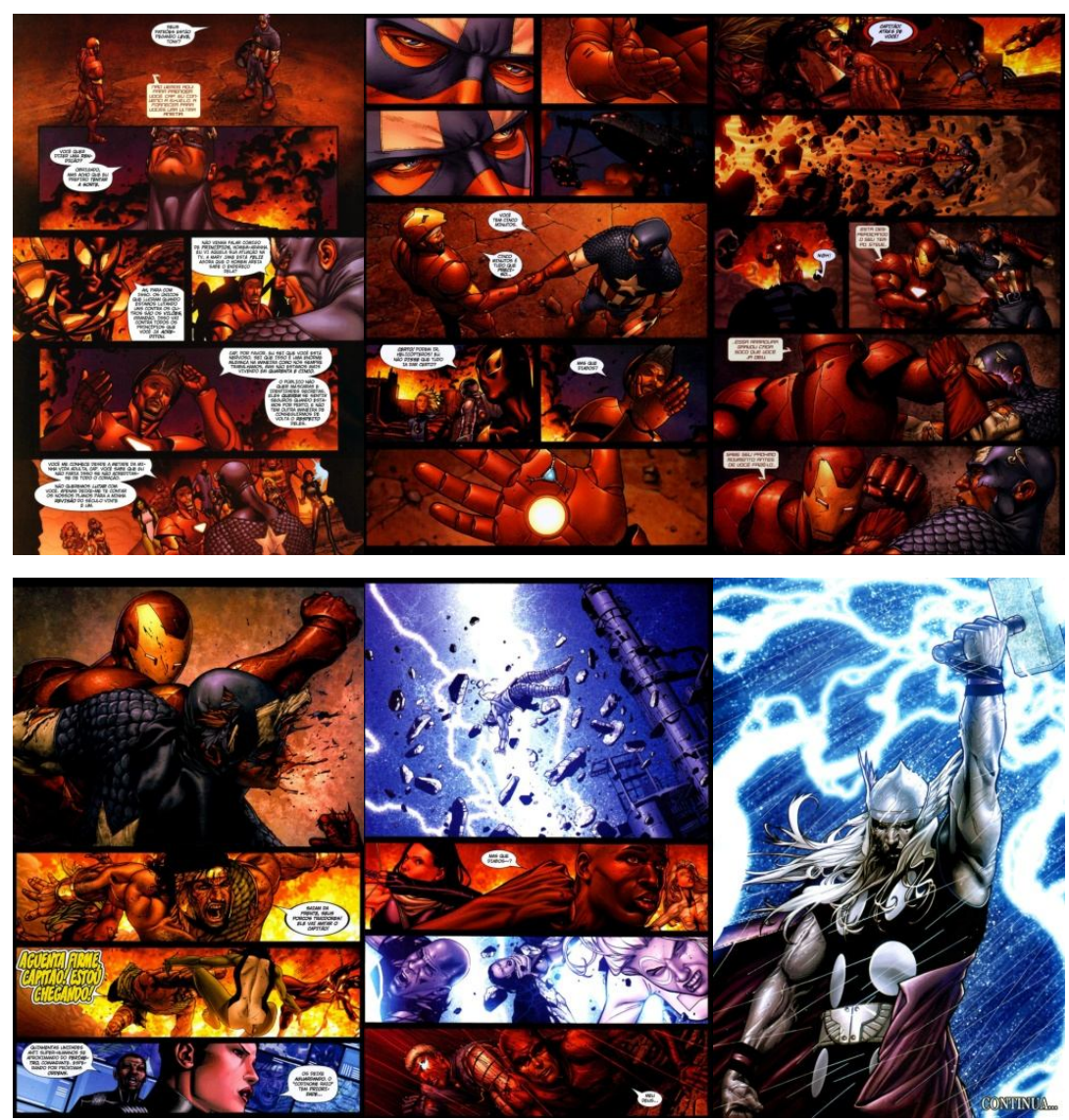

Civil War, 03. Sequência de emboscada aos rebeldes. Nova York: Marvel Comics, 2006.

Na sequência acima o Homem de Ferro e o Capitão América são desenhados a partir do plano conhecido por plongée, de cima para baixo, equilibrando os dois personagens, porém nos quadros seguintes passamos a acompanhar os eventos pela perspectiva de apenas um deles, o Capitão América.

Convém destacar o recurso de fala utilizado por Mcniven para o personagem do Homem de Ferro, uma vezque o contomo do balão de fala 
CAШARI, Victor. Polític a e terrorismo na série Guerra Civil da Marvel Comics. Domínios da Ima gem, Londrina, v. 8, n. 16, p. 146-167, jun./dez. 2014.

ISSN 2237-9126

e a fonte da letra são utilizados para demonstrar o som metálico produzido pela amadura enquanto as formas convencionais são utilizadas nos momentos em que esse retira sua máscara.

A disposição e o formato dos quadros favorecem o dinamismo da leitura, ainda que as elipses e a quantidade de diálogos sejam ferramentas que formalizem esse controle.

O plano de close up utilizado nos primeiros quadros da página dois indica a desconfiança do Capitão América em relação às propostas do Homem de Ferro. Percebendo a amadilha, o Capitão América faz uso de um dispositivo que desliga a amadura de seu rival dando início ao confronto. De dentro de sua nave a comandante Hill dá a ordem e liberta a figura de Thor ${ }^{9}$, que desequilibra o conflito e termina com a morte do superherói Golias graçasa um raio desferido pelo clone do deus nórdico.

A quarta edição começa com a Mulher Invisivel criando um campo de proteção para os rebeldes, protegendo-os da violência do clone para que esses consigam escapar. As páginas seguintes a presentam o lamento dos heróis pela morte de Golias, a contestação da validade da lei de registrose a reorganização do grupo rebelde. Os momentos ma is dra mátic os fic am reservados para o enterro do herói gigante, quando Tony Stark recebe um action figure do Homem de Ferro de presente da mãe do menino Damien, a mesma que antes cuspira em sua cara, ouvindo a frase "eu também queria Ihe dar isto, o brinquedo favorito do meu filho Damien desde que ele tinha três anos de idade, só para lembrarvocê porque está lutando" (MILAR; MCNIVEN, 2010, p. 97). A a mbiguidade da cena permite ao leitor a ferir duas coisas: que Tony Stark está lutando para evitar outros acidentes como o que ocorreu na primeira edição, ou que ele está lutando apenas por si mesmo, seus desejose vontades.

\footnotetext{
9 Nesse momento todosacreditavam que Thor estivesse morto, e mais ta rde ficaria cla ro que esse personagem seria, na verdade, um clone do deus do Trovão, criado por Tony Stark, a partir de uma mecha de cabelo.
} 
CAШARI, Victor. Política e terrorismo na série Guerra Civil da Marvel Comics. Domínios da Ima gem, Londrina, v. 8, n. 16, p. 146-167, jun./dez. 2014.

ISSN 2237-9126

Nessa edição a Mulher Invisivel também abandona o grupo próregistro e passa à clandestinidade, enquanto nas páginas finais o leitor é agraciado com o Sr. Fantástico recrutando, ainda que "temporariamente", um grupo de supervilões para prender os heróis dissidentes.

$\mathrm{Na}$ medida em que a série vai se aproximando de seu final, as questões morais começam a aparecer, desnudando o posicionamento político da editora e de seusautores que não mais permanecem apenas nas entrelinhas.

A a liança entre o grupo pró-registro e os vilões, a dissidência da Mulher Invisível e agora a do Homem-Aranha, levam o leitor a questionar a opção feita por Homem de Ferro, Sr. Fantástico e outros. Outrora principal ferramenta de propaganda dos aliados do govemo, o Homem-Aranha em sua tentativa de fuga é alvejado poragentes da S.H.I.E.L.D e perseguido por vilões em esgotos subterrâneos a té ser salvo pelo J ustic eiro.

Figura 8

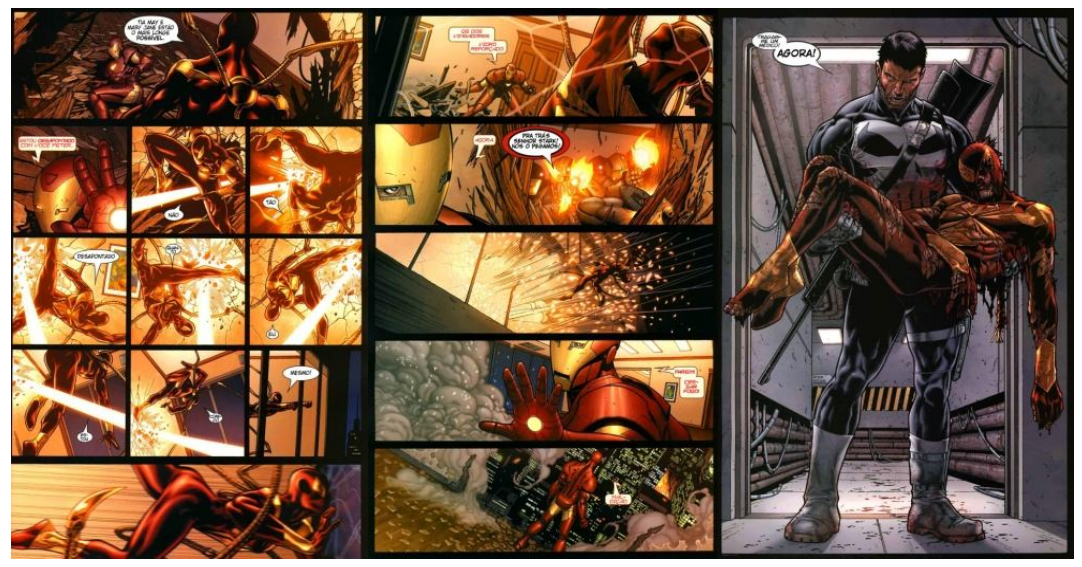

Civil War, 05. Fuga do Homem-Aranha. Nova York: Marvel Comics, 2006.

A sequência de imagens acima apresenta a utilização de diferentes planos e culmina com a entrada do personagem Justiceiro carregando o Homem-Aranha em seus braços. Os autores fazem uso de um plano de conjunto, aquele que não mostra todo o cenário em que a cena se passa, 
CAШARI, Victor. Polític a e terrorismo na série Guerra Civil da Marvel Comics. Domínios da Ima gem, Londrina, v. 8, n. 16, p. 146-167, jun./dez. 2014.

ISSN 2237-9126

mas destaca os dois personagens ao retratá-los em uma página inteira. Os heróis dissidentes, apesar da desconfiança, aceitam a presença do J ustic eiro devido a seu treinamento militar, que havia permitido a invasão da Prisão de Zona Negativa, criada por Tony Stark e Reed Richards para a prisiona ros super-heró is rebeldes.

A existência da Prisão de Zona Negativa na história é mais um indício do lado escolhido pela editora. A representação da Prisão de Guantánamo só pode aludir aos crimes, privação de direitos e torturas que foram perpetrados pelo govemo estadunidense, alvo de críticas e denúncias de desrespeito à Convenção de Genebra, pelo menos desde 2003. Mais de setecentos presos foram encarcerados após os atentados ao World Trade Center, permanecendo sem uma acusação formal durante anos sob suspeita de terrorismo e envolvimento com a rede Al- Qaeda.

A retidão moral do Capitão América é atestada, mais uma vez, na edição de número cinco, durante uma reunião de planejamento para a invasão da Prisão de Zona Negativa, quando os heróis são abordados por do is supervilões que esperam poder ajudar na luta contra o Homem de Ferro e são alveja dos e mortos pelo J ustic eiro.

Figura 9

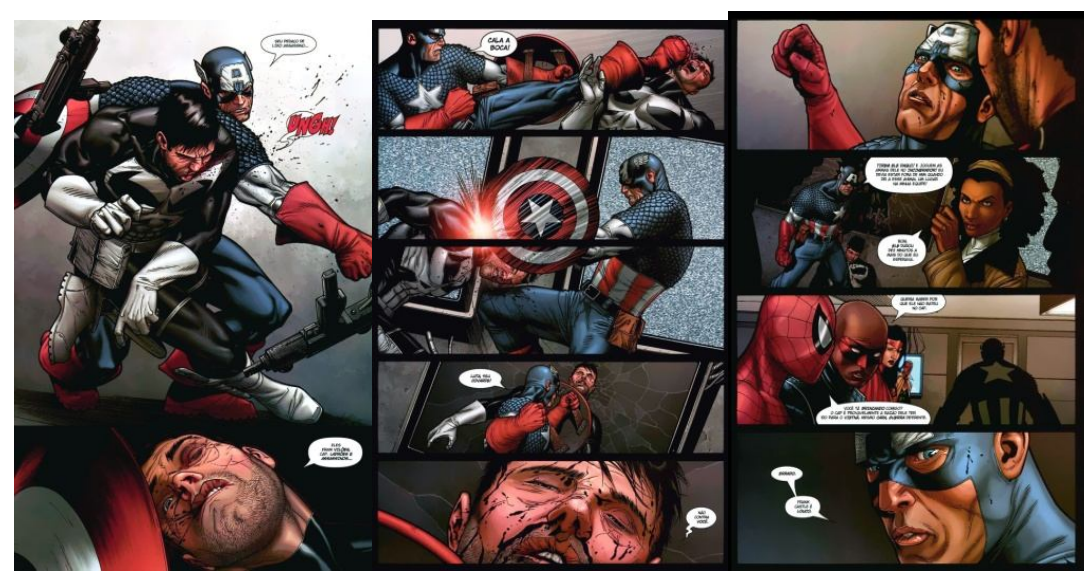

Civil War, 06. Combate entre Capitão América e Justic eiro. Nova York:

Marvel Comics, 2006. 
CAШARI, Victor. Política e terrorismo na série Guerra Civil da Marvel Comics. Domínios da Ima gem, Londrina, v. 8, n. 16, p. 146-167, jun./dez. 2014.

ISSN 2237-9126

A sequência de imagens acima mostra o Capitão América reagindo ao assassinato dos dois vilões cometido pelo Justiceiro que, em contrapartida, não esboça reação alguma. No penúltimo quadro, o Homem-Aranha procura a proximar a figura do Justiceiro e sua a tuação no Vietnã com a do Capitão América em sua luta contra o govemo, enquanto no último quadro temos mais um plano close up do rosto do Capitão América que marca sua posição acerca dos valores que ele representa negando a aproximação feita pelo Homem-Aranha.

Os rebeldes prosseguem com o plano de invasão e libertação dos super-heróis prisioneiros na Zona Negativa quando são surpreendidos pelo Homem de Ferro e seus seguidores, ação que põe fim à sexta edição. A última edição apresenta a Guerra Civil em seu momento ma is violento. Os dois lados em conflito são teletransportados de dentro da prisão para o centro de Nova York, onde o combate ganha enomes proporções. Contra a legião de clones utiliza dos pelo Homem de Ferro, os dissidentes ganham o apoio de Namor e seu exército do mar. Nesse momento, os mais populares personagens da editora apoiam o Capitão América e os rebeldes, deixando o Homem de Ferro praticamente isolado.

As páginas finais levam o Capitão América da vitória ao martíno, fazendo prevalecer a retidão moral e os valores que ele representa desde sua criação.

Figura 10

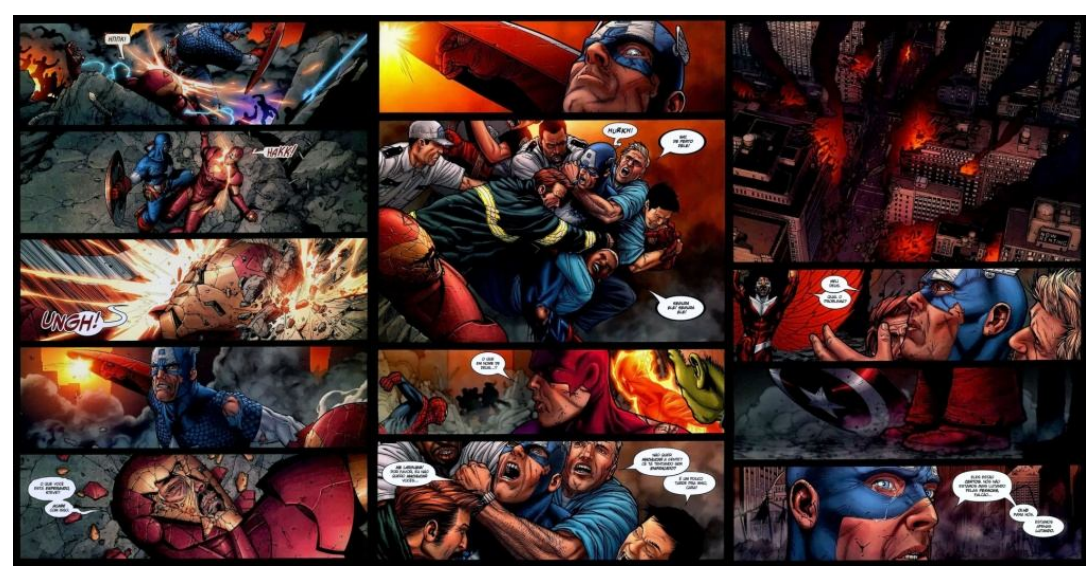


CAШARI, Victor. Política e terrorismo na série Guerra Civil da Marvel Comics. Domínios da Ima gem, Londrina, v. 8, n. 16, p. 146-167, jun./dez. 2014.

ISSN 2237-9126

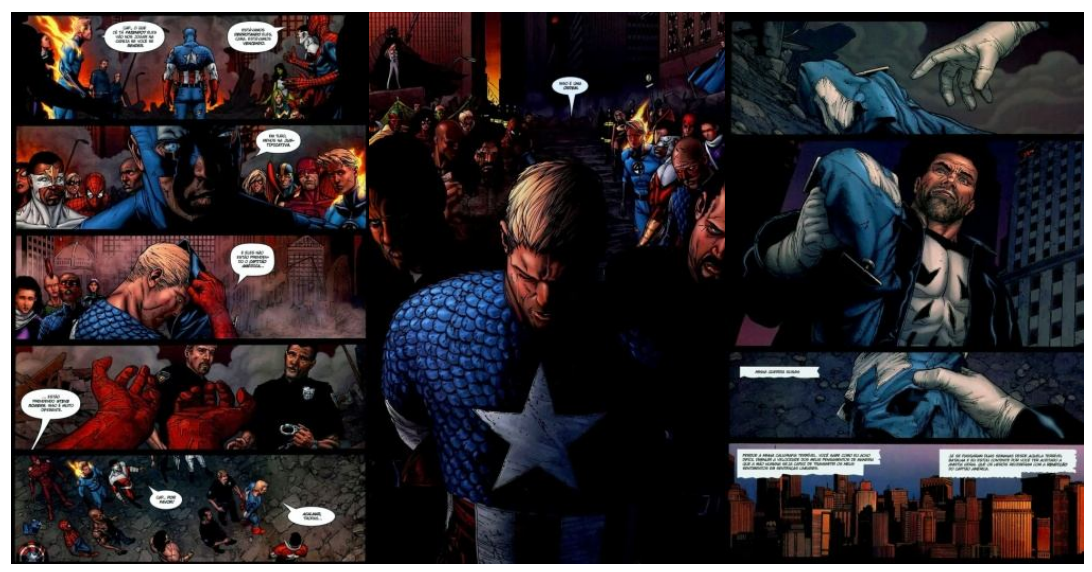

Civil War, 07. Sequência da rendição do Capitão América. Nova York: Marvel Comics, 2006.

Dividida em cinco quadros, a primeira página altema diferentes planos e pontos de vista, utilizando de linhas cinéticas que indicam o movimento dos golpes desferidos pelo Capitão América contra o Homem de Ferro. O espaço para a fala do líder do govemo indica o espaço de tempo de hesita ção do herói rebelde diante da fragilidade de seu adversário, o tempo necessário para a intervenção de bombeiros, paramédicos e outros representantes da sociedade civil, que se jogam sobre os combatentes não a favor de um e contrário ao outro, mas para chamar a atenção para a violência e destruição que a Guerra Civil estava causando, como pode ser observado na página três.

O detalhe do escudo caindo ao chão demonstra a perplexidade do Capitão América, que aparece em close up, no último quadro, com uma lágrima escorrendo do rosto. O herói vitorioso sacrifica-se em prol do bem comum e, a o tirar a máscara, deixa claro que os valores que ele representa não poderiam ser presos ou derrotados. A imagem do Capitão América algemado, em primeiro plano, a expressão atônita dos outros heróis ao fundo, e o jogo de luz e sombras martiniza o personagem a partir de sua escolha a o mesmo tempo em que engrandece sua atitude. 
CAШARI, Victor. Política e terrorismo na série Guerra Civil da Marvel Comics. Domínios da Ima gem, Londrina, v. 8, n. 16, p. 146-167, jun./dez. 2014.

ISSN 2237-9126

As últimas páginas da publicação são dedicadas à celebração do grupo "vitorioso", da implementação do Projeto Iniciativa - que tem como objetivo um grupo de super-heróis treinados e respondendo ao govemo em cada um dos cinquenta estados da união - e da sagração individual de seus agentes. O Homem de Ferro toma-se diretor da S.H.I.E.L.D., Hank Pym capa da revista Time e Sue Storm volta para Reed Ric hards.

Apesar da vitória do govemo, e de uma última página que utiliza de tons dourados, iluminando a fala de Tony Stark de que "o melhor ainda está por vir", as críticas construídas pela editora prevalecem e seu discurso político não se mantém neutro ou isento das questões suscitadas pelo contexto em que a obra foi produzida.

Figura 11

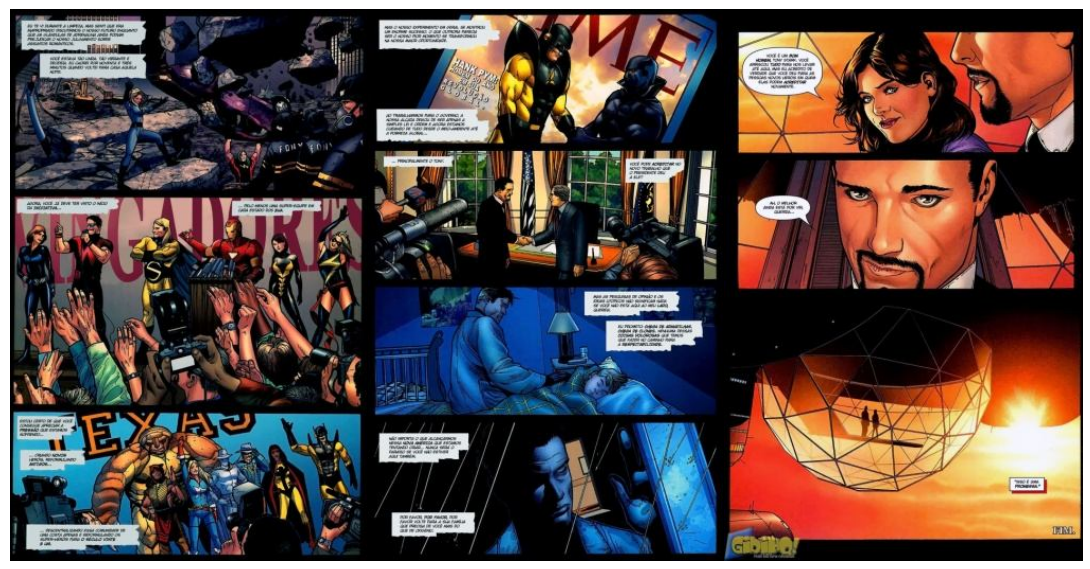

Civil War, 07. Triunfo dos adeptos da Lei de Registro. Nova York: Marvel Comics, 2006.

\section{Considerações finais}

No artigo intitulado "A saga Civil War nos quadrinhos da Marvel Comics: sua representação a póso 11/09", Leandro Vicenti e Carla Femanda da Silva (2011) analisam o discurso político produzido pela editora evidenciando a exaltação de um novo modelo de herói a ser seguido. 
CAШARI, Victor. Política e terrorismo na série Guerra Civil da Marvel Comics. Domínios da Ima gem, Londrina, v. 8, n. 16, p. 146-167, jun./dez. 2014.

ISSN 2237-9126

O discurso que se destaca não é apenas de apoio à política militar norte-americana, mas da própria morte conceitual do antigo modelo de heroísmo, onde se evidencia uma representação do momento de ruptura vivido pela sociedade. Deixando claro o discurso de que até os mais dedicados idealistas podem estar enganados, e devem submeter-se ao a pelo govema mental de uma luta unificada contra os males que se elevam contra a nação norteamericana, independentemente de tal luta confrontar o própro ideal de soberania do país. (VICENTT; SILVA, 2011, p. 6)

Para Vicenti e Silva, a vitória do personagem do Homem de Ferro significaria mais que uma escolha do lado vencedor da guerra. Seria uma evidência do posicionamento político adotado pela editora diante das questões referentes a o próprio contexto estadunidense durante os anos da administração Bush e suas políticas intemas e extemas decorrentes dos atentados do 11 de setembro.

Segundo o artigo, a editora defenderia a ação do govemo e a supressão das liberdades civis em prol da segurança da nação, "a Marvel Comics finaliza sua representação dos atentados de 11/09, sob o discurso de que, independente do contexto, o verdadeiro herói é aquele que se levanta contra o terror e que para proteger seu país sacrific a até mesmo seus direitos democráticos" (VICENT1; SILVA, 2011, p. 27).

Diversos elementos escapam à leitura dos autores, uma vez que em sua análise eles não destacam os momentos de autoquestionamento do personagem Homem de Ferro, a decisão de dois importantes personagens, tanto para o enredo quanto para a imagem da editora, Sue Stom, a Mulher Inviśvel e o Homem-Aranha, de decidirem apoiar os rebeldes e o Capitão América; a crítica moral presente na aliança com os supervilões na tenta tiva de vitória a qualquer preço, além das diferentes formas de narrativa que não dependem exclusivamente do enredo construído pelo texto, mas que podem ser construídas através da imagem, como por exemplo, a exaltação 
CAШARI, Victor. Polític a e terrorismo na série Guerra Civil da Marvel Comics. Domínios da Ima gem, Londrina, v. 8, n. 16, p. 146-167, jun./dez. 2014.

ISSN 2237-9126

das escolhas e ações do Capitão América nos momentos fina is da série, ou mesmo a valorização de sua retidão moral durante todo o a rco de histórias.

A rendição do Capitão América o aproxima da imagem mítica do Cristo que, redentor da humanidade, abre mão da própria vida para expurgar ospecados do Homem.

Outros elementos como a trajetória histórica da editora diante de circunstâncias parecidas, um olhar mais panorâmico capaz de englobar as outras publicações do peńodo, como as Guerras Secretas e a Invasão Secreta, podem servir, a inda, como elemento importante para relativização de tal a poio. As tra jetónias históric as e os signific a dos simbólicos de cada um dos personagens também devem ser levadas em consideração, principalmente quando é possivel afimar que as escolhas temáticas não foram de forma alguma aleatónias, mas indiscutivelmente políticas.

A escolha por uma referência a um dos mais marcantes eventos da história dos Estados Unidos e a estratégia de marketing utilizada na divulgação da série desde seu primeiro número, "de que lado você está?", convidando o leitor a se posicionar, indica, ao construir nas entrelinhas do discurso, mais que um posicionamento crítico e efetivo acerca das políticas adotadas pela administração Bush, mas uma verdadeira tentativa de intervenção social, falando diretamente ao público e sob a pretensão de neutralidade apresentar uma representação dos conflitos rea is sob a forma de questões presentes no universo Marvel.

Podemos então observar a importância do conhecimento das especificidades narrativas da linguagem dos quadrinhos para a compreensão dos signos cultura is e dos valores ideológicos veiculados por meio desse importante meio comunicador no contexto estadunidense. As tiragens de mais de trezentos mil exemplares e sua relevância para a compreensão das lutas por representação presentes durante todos os oito anos da administração Bush indicam o apelo que a trama exerceu em seu público e que a leitura das histórias em quadrinhos pode e deve ser 
CAШARI, Victor. Polític a e terrorismo na série Guerra Civil da Marvel Comics. Domínios da Imagem, Londrina, v. 8, n. 16, p. 146-167, jun./dez. 2014.

ISSN 2237-9126

respeitada, levada em consideração pelos meios acadêmicos em suas variadas tentativas de compreensão e explicação da realidade social.

\section{Referências}

CHARTIER, Roger. O mundo como representação. Estudos avançados, São Paulo, v. 5, n. 11, 1991.

EISNER, Will. Quadrinhos e arte seqüencial: princípios e práticas do lendário cartunista. São Paulo. Martins Fontes, 2010.

HOBSBAWM, Eric. Trocando mito por história. Estado de São Paulo, 11 set. 2011. Entrevista concedida a Laura Greenhalg. Disponível em: http:// www.esta da o.com.br/ notic ias/geral,troca ndo-mitos-por-historia-imp771081. Acesso em: 8 ago. 2012.

MCCLOUD, Scott. Desvendando os quadrinhos. São Paulo: M.Books do Brasil, 2005.

MILAR, Mark; MCNIVEN, Steve. Guerra civil. São Paulo: Pa nini books, 2010.

RAMOS, Paulo. A leitura dos quadrinhos. São Paulo: Contexto, 2010.

SMITH, J ordan Rendell. 9/11 Tragicomix: allegories of national trauma in art spiegelman's in the shadow of no towers. Queen's Joumal of Visual \& Material Culture, n. 1, 2008.

UNITED STATES. H. R. 3162. 2001. Disponível em: http://epic.org/priva cy/terrorism/hr3162.pdf. Acesso em: 20 mar. 2012.

VICENTI, Leandro Gilbran; SILVA, Carla Femanda da. A saga Civil War nos quadrinhos da Marvel Comics: sua representação após o 11/09. Revista história, imagem e narrativas, Rio de J a neiro, n. 13, p. 6-27, out. 2011.

MARVEL Universe Wiki. Disponível em: http://marvel.com/universe/Hill,_Maria\#ixz2IfM2hGL9. Acesso em: 25 nov. 2013. 